overheated by gas-lights, with doors closed and windows fastened and barricaded, is highly to be deprecated as detrimental to health. The time at my disposal would not admit of my entering upon the details of the most approved methods of ventilation of rooms; however, there is no great difficulty in providing sufficient ventilation if only the hot and vitiated air be allowed to escape at the top of the room.

In conclusion, I would observe that the system of house-drains and their ventilation which I have brought under your notice, is that which was adopted and recommended by Mr. George C. Henderson, Architect and C.E., of Dublin (who, in conjunction with me, examined many houses), and by myself. Neither he nor I, however, claim credit for originating either the system, as a whole, or any of its details.

In the exhibition of sanitary appliances attached to this meeting may be seen models of the system, and also of the several details connected with it, which have been made by Messrs. Maguire \& Son, of Dawson-street, Dublin, contractors for sanitary improvementsan examination of which is invited. Mr. Maguire will show you intercepting ventilating-traps, syphon and other traps of all kinds, for every purpose bearing upon household sanitary arrangements, the mode of ventilating soil-pipes, and the methods for disconnecting waste and rain pipes from house-drains. He has also a model to show the danger of discharging two or more water-closets, \&c., through syphon-traps into one soil-pipe without ventilation, whereby discharge through one untraps the other. An inspection of these and the many other sanitary appliances exhibited will, I feel confident, afford gratification to all interested in the subject of household sanitary reform.

PROTOXIDE OF NITROGEN AS AN AN ASTHETIC.

M. BERT, in removing a tumour of the breast, has again employed protoxide of nitrogen under pressure. The operation lasted fourteen minutes, and the patient experienced no accident. As the administration, according to M. Bert's method, is difficult, it is proposed to give it at first under the atmospheric pressure, and then, to profit by the anæsthesia it causes, to give chloroform. In this way the excitement the first inhalations of chloroform cause may be avoided.-L'Union Médicale.

S. W. 
except some trouble in securing the main artery, no serious impediment was met with-very little blood being lost and the operation a very rapid one. A suspicion of hardness, barely perceptible owing to the extreme distension of the thigh, gave rise to a dread of infiltration into the thigh, to prevent which a moderately tight bandage was applied from the body down, causing a steady flow of fluid from the face of the stump. The patient was put to bed in a cold and almost pulseless state, but under the application of hot-water bottles to the extremities and trunk he slowly revived, this state being succeeded in about two hours by high fever and a pulse varying from 130 to 140 . On the day following the operation he was quiet and drowsy, and slept for a few hours towards evening, his recovery from this time being steady, though retarded by some unfavourable symptoms-notably a large pyæmic abscess which formed over the sacrum, causing great constitutional disturbance. This abscess, however, opened on the fifteenth day after operation, affording great relief and an immediate amelioration of his condition.

The ligatures came away on the eleventh day, and the patient was able to be up on October 1. The after-treatment was simple: full diet, beef, eggs, two glasses of whisky and three of wine every day, for the first week, then gradually diminished; tonics-especially compound tincture of bark, chlorate of potash, and carbonate of ammonia-a combination which agreed with him admirably-and sedatives; his bowels being always carefully regulated. A further complication arose about ten days after the operation-namely, swelling of the hands and face-yielding, however, to a mild diuretic treatment.

\section{CURARE IN HYDROFHOBIA.}

The N. Y. Medical Record of August 9th contains the report of a case of hydrophobia (rabies) successfully treated with curare by Dr. Offenberg. The use of the remedy, which was given hypodermically at first in two doses respectively of gr. $\frac{1}{3}$ each, was commenced about three hours after the sudden outburst of the attack; subsequently the dose was increased to gr. $\frac{6}{13}$ at intervals of about half an hour. After the fifth of these latter injections intense symptoms of paralysis rapidly developed-within one minute-the convulsions had become less severe in intensity and duration; and an hour af ter the last subcutaneous injection, occurred the last convulsion that the patient, a girl aged twenty-four, had. It was scarcely more than an 'irregular convulsive inspiration, and in great contrast to the violence of the convulsions at the outset of the attack. Twice after the last injection, and following a short convulsion on both occasions, the respiratory movements ceased altogether. Respiration, however, was at once restored by strong pressure upon the abdomen and thorax. The patient recovered perfectly. 
and alone with the responsibilities of practice in after-life. If the Dublin student does not practically know his business, he is utterly inexcusable. 'To what market, then, is he to carry his knowledge? To two-the colonial and the English. Australia, South Africa, and India are all lucrative fields for practice. Those who are fond of riding and of an out-door life will find here free scope for their tastes as well as their occupations. In a new settlement a minimal sum is generally guaranteed by the residents to induce a medical man to pitch his camp among them. If the little colony prospers and he is popular, his fortune is made. At the worst he has only lost his time, and he can transfer his capital-his knowledge-to another locality; or, should he prefer the market nearer home, he may begin with an assistantship to an English practitioner. In England, Dublin qualifications are in high repute, and an assistantship is easily obtainable there of the immediate value of $£ 120$ to $£ 140$ a year, with the hope in some cases of obtaining ultimately a partnership in his principal's practice, or perhaps succession to the whole of it. If he be possessed of some capital he may purchase the goodwill of a practice with the transfer of Union appointments and clubs. This is to some extent a hazardous proceeding, but a preliminary assistantship or partnership would obviate some of the risks. For the reason stated above-viz., the greater attractions a commercial career has to offer in England, there is not in that country a plethora of doctors-there is room and fair play for many an earnest, well-trained man.

Stewart Woodhodse, M.D.

LEAD PALSY.

Friedlander (Virchow's Archiv, 1879, p. 24), à propos of a fatal case of lead paralysis with muscular atrophy, the details of the autopsy on which he gives with great minuteness, thinks that the lesions he found authorise him in laying down the following conclusions :--Lead causes the appearance of a functional disturbance of muscle, to which is soon added a disturbance of nutrition, characterised by the proliferation of the nodules and the diminution of the volume of the muscular fasciculi. Secondary degeneration of the nervous fasciculi supplying the affected muscle then follows. From this destruction of the nervous trunk paralysis results, and this paralysis, which is peripheral in character independently of any modifications already undergone by the muscle, causes its rapid atrophy. Dr. Dejerine also has recently laid before the Société de Biologie the results of his researches on the same subject. In three cases out of five he found degeneration of the medullary roots. 'The anterior cornua were not affected.-Archives Gén. de Méd., Août, p. 213. 
the N. and N.E. of Ireland, while vivid lightning was seen occasionally in Dublin from $9 \cdot 30$ p.m. to midnight. At this time tropical heat was felt in the S.W. of France, the thermometer rising to $100^{\circ}$ in the shade at Biarritz and Rochefort. On the 17 th the weather again became very broken in the British Islands. On this day a violent rainstorm caused unprecedented damage to the London and North-Western Railway in North Wales. In the last week some very deep atmospherical depressions crossed the United Kingdom from S.W. to N.E. They caused fresh to strong S.W. gales generally, and destructive rainfalls in England. On the afternoon of the 28 th the barometer fell below 29 inches over the N. of Ireland and nearly the whole of Scotland-the 6 p.m. reading at Mullaghmore, near Sligo, being 28.74 inches. On the 31 st an anticyclone advanced over the kingdom from the westward, and the weather temporarily improved. In Dublin the atmosphere was foggy on the 3rd, $10 \mathrm{th}, 11 \mathrm{th}$, and $20 \mathrm{th}$; lightning was seen on the $12 \mathrm{th}, 21 \mathrm{st}$, and $22 \mathrm{nd}$; and high winds were felt on the 12 th, 17 th, 21 st, 22 nd, and from the 25 th to the 29th inclusive. Bright lunar rainbows were seen at Bray on the evening of the $28 \mathrm{th}$, and next day there was a heavy hailshower at Lough Bray.

\section{PERISCOPE.}

\section{Edited by G. F. Duffer, M.D., F.K.Q.C.P.}

\section{SALICYLIC ACID IN ENTERIC FEVER.}

IN an able communication on "The Physiological and Therapeutical effects of Salicylic Acid and its compounds" (N. Y. Med. Journal, Aug., 1879), Dr. William O. Moore sums up his remarks as to the treatment of enteric fever by this drug as follows:- "1. Salicylic acid and its salts have a decidedly beneficial effect in typhoid fever, in reducing the temperature and thereby decreasing the mortality. 2. That its tendency is to shorten the duration of the disease by its antiseptic properties. 3. That the salicylate treatment is equal to any other antipyretic form of medication. 4. That there is every reason to suppose that the salicylate, combined with the cold-water treatment, would excel all other methods. 5. That a large dose of one drachm of the salicylate of soda acts better given at once than divided doses. Such a dose is sufficient for twentyfour hours." Dr. Moore observes that he has collected 800 cases, in which the mortality was 11 per cent., where the antipyretic treatment was carried out by means of quinine and cold baths. He thinks that 300 cases which he has collected, treated with salicylates alone, will compare very favourably with the above, the mortality being $11 \frac{1}{2}$ per cent. This is a great improvement over the expectant or symptomatic 
treatment, in which the mortality in 1,718 cases was 27 per cent.; and he doubts not that, if the cold-water treatment combined with the salicylate method were adopted, the percentage of mortality would come down to 10 or even 8 per cent.

\section{EARLY SYPHILITIC AFFECTIONS OF THE NERVOUS CENTRES.}

Prof. Mauriac closes a long and able paper on this subject with the following deductions from the facts and researches at his command:1. Syphilis may attack the nervous oentres at a very eanly period after the initial lesion. 2. The early cerebro-spinal lesions are those which develop during the virulent period of the malady - that is to say, during the first two or three years. 3. There are degrees in this precocity of the cerebro-spinal syphiloses. The first includes those which set in within the first twelve months; the second those which develop in the second or third year of the constitutional malady. Statistics seem to show that those of the first degree are mere common than those of the second. 4. Among the early visceral localisations of syphilis, those in the cerebrospinal system are incomparably the most numerons. 5. They are also the most dangerons. Their gravity does not increase with their diathetic age. Those which develop during the first months of syphilis are as formidable as those which belong to the more advanced stages of the malady. 6. All the forms, all the degrees, all the phenomenal combinations that constitute the symptomatology and the processus of the localisations of syphilis in the neural system, are met with in the early as well as in the late cerebro-spinal syphiloses. 7. Certain symptomatic complexes, however, seem to predominate. The most frequent are those which consist in an attack of hemiplegia, involving the whole of one side of the body. 8. Among the attacks of hemiplegia, the syndroma comprising right hemiplegia and aphasia is the most common. 9. The paralytic forms are much more common than the convulsive or epileptic, in the early cerebral syphiloses. 10 . In the cerebro-spinal syphiloses the psychical troubles and the incoordination of the movements are never systematised as they are in mania, general paralysis, and locomotor ataxia. 11. The absence of systematisation in the cerebro-spinal syphiloses must be regarded as one of their chief characteristics. The only exception is in the case of the syndroma of right hemiplegia and aphasia. 12. Early localisations of syphilis in the spinal cord are much less common than in the encephalon. 13. The lesions which seem to belong to the early cerebro-spinal syphiloses are diffuse or, more frequently, circumscribed hyperplastic effusions into the cortical layer of the brain and pia mater, and changes in the Sylvian arteries with consecutive ischæmic softening. 14. In some cases of early cerebro-spinal syphiloses that terminated fatally no lesion was found, but at that time the existence of arterial syphilis had not been recognised. It may be presumed that 
death had resulted from sudden anæmia of the nervous centres that are essential to life. 15. With regard to the etiology of the early cerebrosyphiloses only very vague conjectures can be advanced. In most of the cases the initial lesion as well as the consecutive cutaneous and mucous manifestations were very mild in character. 16. The general cause of the constitutional malady is not modified by the appearance of early localisations in the nervous centres. 'The other manifestations develop before, during, and after the localisation in the neural system, without presenting any deviations from their usual forms, degrees, course, or topography. 17. The precocity of the cerebro-spinal syphiloses furnishes no special indication with regard to treatment. Whatever may be the age of the constitutional malady, the localisations in the nervous centres demand the same specific medication. The peculiar conditions of each case furnish the secondary indications relative to the choice, doses, and combinations of the two specific agents.-Annales de Dermatol. et de Syphilig., Vol. X., No. 3, and N. Y. Med. Record.

\section{THE SUDDEN DEAFNESS OF SYPHILIS.}

Is an article on the above subject in the American Journal of the Medical Sciences for July, by Dr. Sexton, that gentleman adduces the following conclusions:- " 1 . Syphilitic affections of the ear inducing sudden deaf. ness are of exceptional occurrence; and 2. They would seem to be induced by a pre-existing hyperæmia in the ears, excited by sympathetic relationship or by an intercurrent attack of aural mucous catarrh. 3. The attacks are characterised by their sudden occurrence, and both ears are usually affected simultaneously, although the contrary sometimes takes place. 4. The deafness is always very great. 5. This syphilitic affection speedily causes a disarrangement of the integrity of the chain of ossicles-most likely at the malleo-incudal joint, probably, in some instances, at the stapedo-incudal joint, or both of these. The movements of the stapes in the oral window are also likely to be interfered with. The two first-mentioned conditions serve to explain the noises in the ears, and the autophony; the last-mentioned condition would increase the anomalies of hearing. 6. The affection does not depend, so far as we know, on anomalies of any portion of the labyrinth, although the latter, of course, is liable to invasions from syphilis with the nature of which we are as yet unfamiliar. 7. The disease is usually unattended by pain in the ears, it is non-purulent, and its incurability is a characteristic."

\section{PILOCARPIN IN INTERMITTENT FEVER.}

Dr. Gaspar Griswold, House Physician to the Bellevue Hospital, New York, gives, in the N.Y.Med. Record of August 16th, an account of seven cases of intermittent fever treated by the hypodermic injection of one-fifth of a grain of muriate of pilocarpin, given as soon as possible 
after the derelopment of the chill. From these cases he thinks it seems fair to conclude:- "1st. That the muriate of pilocarpin, administered hypodermically, will promptly cut short the chill of malarial intermittent fever. 2nd. That in a large proportion of cases so treated the paroxysm aborts, terminating in the sweat caused by the pilocarpin, there being no hot stage. 3rd. That such abortion of a paroxysm is in itself sufficient to effect a cure in many cases. 4th. That such abortion of a paroxysm is a valuable adjuvant to treatment with quinine during the intervals. 5th. That a dose of pilocarpin sufficient to produce this effect acts gently, without causing exhausting diaphoresis or unpleasant ptyalism. The promptness with which an adequate dose of pilocarpin interrupts a chill is suggestive of its possible efficacy in cases of pernicious intermittent fever, where prevention of the full development of a paroxysm is often of the first importance."

\section{FATTY (AMYloid?) DEgeneration OF THE PLACENTA.}

From some remarks made by Dr. Heitzmann on a specimen of fatty degeneration of the placenta presented to the New York Pathological Society by Dr. Putnam-Jacobi, it would appear that although such placentæ present the gross appearances of fatty degeneration, a microscopic examination reveals the fact that the change is chiefly amyloid.N. Y. Med. Record, Aug. 16.

\section{GONORRHEA IN THE MALE.}

IN the treatment of this affection Dr. J. H. Brinton employs carbolic acid in the shape of a solution containing gtt. ij. of the acid to $3 \mathrm{j}$. of lime-water, as a local application in the acute stage of the disease. At the same time cubebs is administered internally in doses of a tablespoonful in half a tumblerful of water, three or four times a day. The dose is pushed until diarrhoea or nausea supervenes, when the quantity is reduced.-N. Y. Med. Record.

THE USE OF IODIDE OF POTASSICM AND CALOMEL IN OPHTHALMIC PRACTICE.

Dr. W. F. Schlaefke has an interesting article on this subject in Vol. XXV., Part 2, of Graefe's Archives. A few cases have been recorded in which iodide of potassium was being employed internally; upon calomel being insufflated into the conjunctival sac a violent inflammation of this mucous membrane immediately took place. Nothing of the kind has been observed so long as only one of these remedies was used. In order to ascertain the cause of this remarkable occurrence, Dr. Schlaefke undertook a number of chemical experiments and experiments upon animals which have led him to the following conclusions :-Iodide of potassium taken internally is very rapidly diffused through the organism, in a short 
time makes its appearance in the various secretions and excretions, and may be found in the tears within a few minutes. Iodide of potassium, taken twice a day in doses of 0.5 gramme, is constantly present in the tears in appreciable quantities. Calomel is but slightly soluble in water, but is ten times more soluble in a $\frac{3}{4}$ per cent. solution of chloride of sodium. Calomel powder dusted into the conjunctival sac is dissolved by the tears. If iodide of potassium be present in the tears at the time the calomel is insufflated, iodate of mercury and iodide of mercury are formed. These substances have a caustic action and give rise to violent inflammation.

H. R. S.

\section{LOCAL TREATMENT OF ECZEMA.}

Dr. Piffard, Professor of Dermatology in the New York University, in a recent article on this subject, advises the hypodermic injection of arseniate of sodium into patches of infiltrated eczema. He uses solutions of one-fifth, one-half, and one per cent. For a single patch of moderate size a single injection of five to ten minims of the one per cent. or onehalf per cent. solution is made. If the patch is larger, or if there are several of them, the weaker solutions are employed, and two or more punctures made in the larger patches, or distributed among the smaller ones. The injections are to be repeated at intervals of two or three days. He has seen no undue reaction from them. [Cf. a former communication on a similar mode of treatment in the Journal of August last, p. 188.-FD.] Another method employed by him to reduce infiltration is the application of some of the native American "acro-nareotics" to the affected parts. Among these, hydrastis and its derivative occupy, in his opinion, the first rank, and next in usefulness the iris versicolor. Of the latter he makes a tincture from the root, which is rubbed up with simple ointment until the alcohol has evaporated. By these means he believes the absorptive function of the capillaries is stimulated_-Boston Med. and Surg. Jour.

S. W.

THE CONSTITUTION OF THE HYMEN, AND CARUNCULA MYRTIFORMES.

Up to the present time one has looked upon the hymen as being composed of a fold of vaginal and vulvar mucous membrane. According to M. Budin nothing is more erroneous. In his opinion the hymen is not a membrane or a special organ, and, in fact, has no existence. If the genitals of a little girl are examined, it will be noticed that what has hitherto been considered the hymen forms a cup-like projection between the labia majora and minora. This projection, as M. Budin demonstrated lately at the Société de Biologie (Jour. des Con. Méd., 7 Août), is only the anterior extremity of the vagina. The form of the vaginal orifice (to call the hymen by its true name) is variable-most frequently it is 
circular. It has not that fragility which for so long a time has been ascribed to it. Very often it is simply stretched without being broken when sexual connexion takes place for the first time. When it is broken there is nearly always loss of blood and pain. The lacerations produced are either simple or multiple. M. Budin has also shown that carunculæ myrtiformes do not occur in women who have not had children. As above stated, the vaginal orifice (hymen) in a large number is not ruptured by the act of connexion, or any pain or loss of blood experienced. When such women are in labour the hymen often opposes a very formidable obstacle to the delivery of the head, and it is only after the rupture of this fold that the infant's head passes. It is for this reason that the stage of expulsion is so much shorter in multiparæ, and it is by this rupture of the vaginal orifice that these carunculæ are, in M. Budin's opinion, produced.

\section{SALACYLATE OF SODA IN CHOREA.}

As the results of but a few experiments as yet in the treatment of chorea by salicylate of soda, Dr. S. Weir Mitchell, of Philadelphia, thinks that the drug promises to be of some value. Dr. Gerhard, who has also used salicylic acid at Dr. Weir Mitchell's request, is satisfied that it is a valuable aid in the treatment of chorea.-Boston Med. and Surg. Jinur., March 27.

\section{THE HYPODERMIC INJECTION OF MORPHIA.}

Dr. H. H. KaNe, of New York city, who has for some time past been collecting statistics on the hypodermic injection of morphia, will cossider it a great favour if members of the profession who see this, and have had experience of the operation, will answer the following questions :-

1. What is your usual.dose?

2. Do you use morphia alone or with atropia?

3. What is the largest amount you have ever administered at one time?

4. Have you had inflammation or abscess at the point of puncture?

j. Have you had any deaths or accidents caused by hypodermic injections of morphia?

6. Do you know of any cases of opium habit thus contracted?

Where there has been an autopsy (5), please state the fact and the results obtained therefrom. All communications will be considered strictly confidential, the writer's name being used only when he gives full consent thereto. Address all letters to Dr. H. H. Kane, 366, Bleeckerstreet, New York, U.S.A. 